\title{
MUTLULUK ve KURUMSAL GELIŞME
}

Tolga AKSOY*

\begin{abstract}
öz
Günümüzde ülkeler arası ekonomik gelişmişlik farklarının yanı sıra, kurumsal gelişmişlik ve mutluluk farklılıkları da iktisatçıların dikkatini çekmektedir. Literatürde ekonomik göstergeler ile mutluluk arasındaki ilişki pek çok çalışma tarafından ele alınmışken, mutluluk ve kurumlar ilişkisi görece ihmal edilmiştir. Bu çalışmanın amacı kurumsal gelişmenin mutluluk üzerindeki etkisini araştırmaktır. Bu amaçla gelişmiş ve gelişmekte olan 131 ülkenin 2005-2016 yıllarını kapsayan veri seti panel veri yöntemiyle analiz edilmiştir. Çalışmanın sonuçlarına göre mutluluk ve kurumsal gelişme arasında pozitif ve anlamlı bir ilişki vardır. Gelir seviyesi daha yüksek olan ülkelerin düşük gelirli ülkelere kıyasla daha mutlu olduğu görülürken, ekonomik büyüme ve enflasyon gibi konjonktürel değişkenlerin mutluluk üzerinde istatistiki olarak anlamlı bir etkiye sahip olmadığı ortaya çıkmaktadır. Bu sonuçlar, mutluluğun salt parasal bir olgu olmadığını ve ülkelerin kurumsal olarak kalkınarak vatandaşlarının refah seviyelerini artırabileceğini göstermektedir.
\end{abstract}

Anahtar Kavramlar: Mutluluk, Yaşam Merdiveni, Kurumsal Gelişme, Panel Veri.

\footnotetext{
* Dr. Öğr. Üyesi, Yıldız Teknik Üniversitesi, İktisadi ve İdari Bilimler Fakültesi, İktisat Bölümü, toaksoy@yildiz.edu.tr, https://orcid.org/0000-0003-0833-8543.
} 


\title{
HAPPINESS and INSTITUTIONAL DEVELOPMENT
}

\begin{abstract}
Nowadays, not only economic development differences, but also differences in institutional development and happiness attract the attention of economists. Although the relationship between economic indicators and happiness is widely discussed in the literature, the relationship between happiness and institutions has been neglected. The aim of this study is to investigate the effect of institutional development on happiness. To that and, data set of 131 developed and developing countries covering the 2005-2016 period was analyzed with panel data methods. According to the results, there is a positive and significant relationship between happiness and institutional development. While the countries with higher income levels are happier than the low-income countries, it appears that cyclical variables such as the rate of economic growth and inflation do not have a statistically significant impact on happiness. These results show that happiness is not merely a monetary phenomenon, and countries can increase the welfare of their citizens by improving institutions.
\end{abstract}

Keywords: Happiness, Life Ladder, Institutional Development, Panel Data.

\section{GíRIŞ}

Mutluluk kavramının iktisatçıların ilgi alanına girmesi Richar Easterlin'in 1974 tarihli "Does Economic Growth Increase Human Lot? Some Empirical Evidence" çalışmasıyla olmuştur. Bu çalışmanın sonucu olarak ortaya çıkan Easterlin Paradoksuna göre, belirli bir zaman noktasında mutluluk gelire göre değişir, ancak zaman içerisinde bir ülkenin geliri arttığında mutluluk artmaz (Easterlin, 1974). Easterlin Paradoksu farklı ülke ve zaman dilimlerini kapsayan pek çok analize konu olmuş ancak bir görüş birliğine varılamamıştır. Mutluluk ve gelir ilişkisi yoğun bir biçimde incelenmesine rağmen, literatürde kurumların mutluluk üzerindeki etkisi ihmal edilmiş görünmektedir. Hâlbuki kurumların insanların refah düzeyleri üzerinde herhangi bir etkileri olup olmadığı, eğer varsa bu etkinin ne derece önemli olduğu sorularını yanıtlamak için mutlulukkurumsal gelişme konusu detaylı olarak incelenmelidir. Kurumsal gelişme mutluluğu artırabilir mi? Kurumsal olarak gelişmiş ülkeler zayıf kurumlara sahip olan ülkelere kıyasla daha mutlular mıdır? Bu çalışmanın amacı kurumların mutluluk üzerindeki etkisini saptamaktır.

North (1990) kurumları politik, ekonomik ve sosyal etkileşimleri biçimlendiren ve belirsizliği azaltan "oyunun kuralları" ya da "insanlar tarafindan geliştirilmiş kısıtlamalar" olarak tanımlamaktadır. $\mathrm{Bu}$ anlamda kurumlar norm, kültür, gelenek ve görenekler, din gibi enformel; anayasa ve mülkiyet hakları gibi formel; ya da ilgili yasalardaki sözleşmeleri tanımlamak ve bunları sözleşmeden doğan işlemlerle uyumlu hale getirmek olarak 
tanımlanabilecek yönetişim şsekline ortaya çıkabilirler (Williamson, 2000). Kurumsal gelişme ülkelerin mutluluk seviyelerini çeşitli açılardan etkileyebilir. İlk olarak gelişmiş kurumlara sahip ülkelerde fren ve denge mekanizmaları daha düzgün çalışır ve böylece politikacılar bireyler tarafından daha iyi denetlenir. Böylece kamu vatandaşların tercihlerini dikkate alarak politikalarını belirler (Frey ve Stutzer, 2000a). Bununla birlikte bireylerin politik süreçlere katılımı artar. Daha özgür toplumlar daha örgütlü olacak, sendikalara, sivil toplum örgütlerine katılımlarla bireyler politik süreçlere katılabilecekleri ve politik sonuçlara etki edebilecekleri için yaşam memnuniyetleri artacaktır. İkincisi, özel mülkiyetin korunması, girişim özgürlüğü ve hukukun üstünlüğü gibi serbest piyasa sisteminin temel gereklilikleri ancak kurumsal olarak gelişmiş ülkelerde sağlanabilir. Üçüncü olarak, politik ekonomi literatürü, mutlulukla demokrasinin pozitif ilişkili olduğunu göstermektedir (Dorn, Fischer, Kirchgässner ve SousaPoza, 2007; Frey ve Stutzer, 2000a, 2000b; Ott, 2010). Demokratik rejimler insanların tercihlerini daha iyi yansıtırlar. Demokrasinin en temel özelliği olan serbest seçimler politikacıların vatandaşların refah seviyelerini görmezden gelmelerini engeller. Aksi takdirde, seçmenler tarafindan yeniden seçilmemekle cezalandırılabilirler. Eğer ekonomik göstergeler iyiyse hükümete olan destek artmaktadır. Uzun vadede, insanların yaşam memnuniyeti mevcut siyasal rejime olan desteği artıracak ve ona meşruiyet kazandıracaktır. Demokrasi kitlesel desteğe ihtiyaç duyduğu için mutlu bir toplum demokrasinin olmazsa olmazıdır. Kaldı ki, mutluluk güven, hoş görü ve kendini ifade etme gibi kavramlarla bağlantılıdır ki bunlar ancak demokratik toplumlarda mümkündür (Inglehart, 2006; Inglehart ve Ponarin, 2013). Ayrıca kurumsal kalkınma ekonomik sömürünün önlenmesi, şiddetin azalması, şeffaflığın artması, yasaların icrası yoluyla belirsizliği ve işlem maliyetlerini azaltarak (Bjørnskov, Dreher ve Fischer, 2010) ve kamu bürokrasisinin etkinliğini ve tarafsızlığını artırarak (Bjørnskov ve Tsai, 2015) mutluluğa pozitif katk1 yapar. Son olarak iktisat literatürü kurumların iktisadi büyüme üzerinde pozitif ve anlamlı bir etkisi olduğunu ortaya koymaktadır (Acemoglu, Johnson ve Robinson, 2001; Rodrik, Subramanian ve Trebbi, 2004; Acemoglu, Naidu, Restrepo ve Robinson, 2019). Böylelikle, kurumlar toplam çıktıyı artırarak dolaylı yoldan da mutluluğu teşvik eder.

$\mathrm{Bu}$ çalışmada ülkeler arası mutluluk değişkenliğini açıklamak için kurumsal gelişmişlik farklılıklarından yararlanılmaktadır. Her ne kadar formel ve enformel kurumların etkilerini incelemek mümkünse de yukarıda tanımlandığı biçimde Yönetişim kavramını "oyunun kuralları" olarak ele almak daha doğru olacaktır. Bu nedenle, kurum değişkeni olarak Dünya Bankası Yönetişim Göstergeleri (DBYG) kullanılmaktadır (Dünya Bankası, 2018; Kaufmann, Kraay ve Mastruzzi, 2010) ${ }^{1}$. Öte yandan, kültür, dil, din gibi enformel kurumlar zamana bağlı olarak değişmezken yönetişim göstergeleri

\footnotetext{
${ }^{1}$ Benzer bir analizi için bkz. Yay, Yay ve Aksoy, 2016.
} 
ülkelerin politik yapılarına göre zaman içerisinde olumlu ya da olumsuz olarak değişebilmektedir. Böylece hem ülkeler arası değişim hem de aynı ülkenin zaman içerisindeki değişimi yakalanabilmektedir. Sonuçları kısaca özetlemek gerekirse, gelişmiş ve gelişmekte olan 131 ülkenin 2005-2016 yıllarını kapsayan analizlerine göre yönetişim ve mutluluk arasında pozitif ve istatistiksel olarak anlamlı bir ilişki olduğu görülmektedir. Ayrıca sonuçlara göre gelir seviyesinin yüksek olduğu ülkelerde mutluluğun daha yüksek olduğu ortaya çıkmaktadır. Bunula birlikte aynı gelir seviyesine sahip iki ülke arasında daha iyi yönetişime sahip olan ülke daha yüksek mutluluk seviyesine sahip olmaktadır.

Çalışmanın bundan sonraki kısmı şu şekilde ilerlemektedir. Birinci bölümde mutluluk ve kurumlar arasındaki ilişkiyi inceleyen ampirik literatür tartışılmaktadır. İkinci bölümde veri seti tanıtılmakta ve betimsel analiz gerçekleştirilmektedir. Üçüncü bölümde ekonometrik analiz ve sonuçları tartışılmaktadır. Son bölümde ise bazı politika önerileri ortaya konacaktır.

\section{LITERATÜR TARAMASI}

İktisat literatüründe mutluluk ve kurumsal gelişmişlik ilişkisini inceleyen pek çok çalışma olmasına rağmen bir fikir birliği olduğunu söyleyemeyiz. Farklı ülke(ler), değişik zaman dilimleri, farklı mutluluk/kurum tanımları ve tahmin yöntemlerine dayanan bu çalışmalar farklı sonuçlara ulaşmaktadırlar. Örneğin, Frey ve Stutzer (2000a) İsviçre'de 6000'den fazla kişiyle yapılan bir ankete dayanan çalışmalarında bireysel siyasi katılım imkânlarının (doğrudan demokrasi) bireylerin mutluluk seviyelerini artırdığını bulmuşlardır. Benzer şekilde Frey ve Stutzer (2000b) doğrudan demokrasi ve yerel özerklik kapsamının mutluluk üzerindeki pozitif etkisinin cinsiyet, yaş ve gelir gibi değişkenlere bağlı olmadığını, dolayısıyla tüm insanların bu demokratik haklardan faydalandığını belirtmektedirler. Dorn, Fischer, Kirchgässner ve Sousa-Poza (2008) ise Frey ve Stutzer'in (2000a, 2000b) bulgularından şüphe duymaktadırlar. Yazarlar dil değişkenini kültürü kontrol etmek için modele dâhil ettiklerinde, doğrudan demokrasi katsayısının geleneksel seviyelerde artık istatistiksel olarak anlamlı olmadığını bulmaktadırlar. Bu sonuç, diğer tüm koşullar aynıyken bile farklı dilleri konuşan bireylerin mutluluğu farklı şekilde tanımladıklarını göstermektedir. Ya da bireylerin kültürel değerleri politik kurumlara baskın olabilirler. Benzer başka bir çalışmalarında ise Dorn vd. (2007) 28 ülkenin 1998 yılında bireysel düzeydeki verilerini kullanarak demokrasi ve mutluluk arasındaki ilişkiyi araştırmaktadırlar. Buna göre, dil ve din gibi kültürel göstergeler ile ekonomik değişkenlerden bağımsız olarak demokrasi mutluluğu pozitif olarak etkilemektedir.

Ott (2005) ve Ott (2010) sirasiyla 78 ve 127 ülkeyi ele alan çalışmalarında yönetişim kalitesiyle ülkeler-arası mutluluk seviyesi arasında pozitif korelasyon, yönetişim kalitesiyle ülke-içi mutluluk eşitsizliği arasında ise negatif korelasyon olduğunu bulmuşlardır. Ancak bu ilişki büyük ölçüde zengin 
ülkelerin varlığından ileri gelmektedir. Örneklem gelire göre bölündüğünde yoksul ülkelerde mutluluk-yönetişim korelasyonunun çok düşük olduğu ve mutluluk eşitsizliği-yönetişim korelasyonunun hem önemli ölçüde azaldığı hem de işaretinin pozitif olduğu ortaya çıkmaktadır. Benzer başka bir çalışmada ise Ott (2011) yönetişim ve mutluluk arasındaki pozitif ilişkinin coğrafyadan bağımsız olduğunu, dolayısıyla daha yüksek mutluluk seviyesi için tüm ülkelerin yönetişim kalitelerini artırmaları gerektiğini savunmaktadır.

Bjørnskov, Dreher ve Fischer (2008) 1997-2000 dönemini kapsayan çalışmalarında, 70 ülkede en az otuz bin katılımcının bilgilerini kullanarak yaşam memnuniyetinin belirleyicilerini araştırmaktadır. Yazarlar DBYG'nin aritmetik ortalaması genel yönetişim olarak kullanıldı̆̆ında, yönetişimin yaşam memnuniyeti ile negatif ilişkili olduğunu bulmuşlardır. Bjørnskov vd. (2010) ise ekonomik ve politik kurumların mutluluk üzerindeki etkilerini 62 ülkenin tekrarlanan yatay-kesit verileriyle incelemektedirler. Sonuçlar, tüm kurumların genel olarak mutluluğu teşvik etmesine rağmen, ekonomik kurumların düşük gelirli (yüksek gelirli) ülkelerdeki siyasi kurumlardan daha güçlü (zayıf) etkiye sahip olduğunu göstermektedir. Bu nedenle düşük gelirli ülkelerde demokrasinin mutluluğu besleyebilmesi için öncelikle belirli bir ekonomik gelişme seviyesine ulaşılması gerekmektedir.

Inglehart ve Ponarin (2013), 42 ülkeyi ve 1981-2007 dönemini kapsayan analizlerinde demokrasinin ekonomik gelişmişliği kontrol ettikten sonra bile mutluluğu teşvik ettiğini savunmaktadır. Bununla birlikte, birçok otokratik rejimin 1990'lı y1llarda demokrasiye geçmesine rağmen mutluluk düzeylerinde dramatik bir artış gözlemlenmemiştir. Bu nedenle 1990'lardan sonra demokrasi ve mutluluk arasındaki korelasyon azalmaktadır. Dolayısıyla, yazarlar demokrasinin mutluluğa neden olmadığını, ancak mutluluğun demokrasiye birlikte var olabildiğini savunmaktadırlar.

Farklı gelir ve gelişmişlik seviyelerindeki ülkeleri bir araya getiren çalışmalara ek olarak literatürde daha az gelişmiş ülkelere odaklanan çalışmalar da mevcuttur. Örneğin Fereidouni, Najdi ve Amiri (2013) yönetişimin Orta Doğu ve Kuzey Afrika (MENA) bölgesinde mutluluk üzerindeki etkisini araştırmaktadır. Yazarlar DBYG kullanarak, 2009-2011 döneminde on dört MENA ülkesinde siyasi istikrarın ve şiddetin yokluğunun, hükümetin etkililiğinin ve düzenleyici kalitenin mutlulukla pozitif ilişkili olduğu sonucuna ulaşmaktadırlar. Ayrıca, tahmin sonuçlarına göre kişi başına düşen GSYİH mutluluğu teşvik etmesine rağmen, eğitim ve işsizlik mutluluk üzerinde istatistiksel olarak anlamlı bir etkiye sahip değildir.

Djankov, Nikolova ve Zilinsky (2016) ise piyasa ekonomilerine geçişe rağmen, Doğu Avrupa ülkelerinde mutluluğun diğer gelişmiş ve gelişmekte olan ülkelere kıyasla anormal derecede düşük olduğunu savunmaktadırlar. Yazarlar iki grup ülke arasındaki mutluluk farkının nedenlerini araştırmak amacıyla 19902014 dönemini kapsayan geniş çaplı anket verilerini kullanmaktadırlar. Tahmin 
sonuçları yolsuzluk kontrolünün ve hükümetin etkinliğinin, mutlulukla pozitif olarak ilişkili olduğunu göstermektedir. Daha da önemlisi, her iki gruptaki bireylerin hükümetin performansı arttıkça daha mutlu olduğunu dolayısıyla da ve mutluluk farkının Doğu Avrupa'da daha fazla yolsuzluk ve daha kötü yönetişimden kaynaklandığını ileri sürmektedirler. Benzer bir çalışmada Nikolova (2016) 1994 ve 2013 yıllarını kapsayan verileri kullanarak, 1990'11 yıllarda oldukça yüksek olan mutluluk açığının zamanla azaldığını ve dönem sonu itibariyle tamamen ortadan kalktığını göstermektedir. Çalışmada, hukukun üstünlüğü geçiş ekonomilerinde mutluluğu teşvik etmesine rağmen, etkisinin ekonomik büyüme ve enflasyon gibi makroekonomik faktörlere kıyasla çok daha küçük olduğu görülmektedir. Dolayısıyla bireylerin ekonomik refah ve istikrara kurumsal gelişmişliğe göre daha fazla önem atfettikleri anlaşılmaktadır.

$\mathrm{Bu}$ çalışmanın odak noktası yukarda tartışılan katkılara benzer görünse de birkaç önemli açıdan farklıdır. Öncelikle, literatürde ele alınan çalışmaların çok büyük bir kısmı tekil ülkeleri (örneğin İsviçre), ya da küçük ülke gruplarını (Doğu Avrupa, MENA bölgesi) kapsamaktadır. Dolayısıyla sonuçların geri kalan ülkeler için geçerli olup olmadığ belirsizdir. Biz ise bu çalışmada 120 ülkenin 2005-2016 dönemini ele alarak hem çok daha geniş hem de daha uzun dönemli bir analiz yapıyoruz. Ayrıca literatür incelendiğinde yöntem ve veri seti ile ilgili problemler göze çarpmaktadır. Örneğin, Ott (2005, 2010 ve 2011) çalışmaları yalnızca korelasyon analizinden ibarettir. Dorn vd. (2008) çok sayıda ülkeyi ele almasına rağmen yalnızca yatay-kesit analizi yapmaktadır. Diğer çalışmaların neredeyse tamamı ise birkaç y1lı kapsayan veri setleriyle kısa dönemli sonuçlara ulaşabilmektedirler. Bu çalışmada kullanılan veri seti hem kesit hem de zaman birimlerine sahip olduğu için panel veri analizi yapılmaktadır. Böylelikle hem zaman etkisi ölçülmekte, hem de dil, kültür gibi zamana bağlı olmayan ama mutluluk ve kurumsal gelişmeyi etkileyebilecek değişkenlerin sonuçlar üzerindeki etkileri arındırılabilmektedir. Son olarak, bu çalışmada yalnızca tek bir kurum (örneğin demokrasi) değişkeni yerine yönetişimin altı farklı bileşenini kullanarak hangi bileşenin hangi ölçüde istatistiksel olarak mutluluğa pozitif katkı yaptığı saptanmıştır.

\section{VERİ SETİ ve BETIMSEL ANALIZZ}

Çalışmada kullanılacak olan mutluluk verisi Dünya Mutluluk Raporu'ndan alınan Yaşam Merdiveni (Life Ladder) değişkenidir. Birleşmiş Milletler (BM) tarafindan ilk olarak 2012 yılında oluşturulan Dünya Mutluluk Raporu mutluluğun küresel durumunu gösteren bir ankettir ${ }^{2}$. Anketin kapsamında kullanılan veriler Gallup World Poll'den gelmektedir ${ }^{3}$. Yaşama dair memnuniyet ve mutluluk ölçümünde esas ve öncelikli olarak kullanılan yöntem Cantril Ladder olmuştur. Bireylere her şey göz önünde bulundurulduğunda

\footnotetext{
${ }^{2} \mathrm{http} / / /$ worldhappiness.report/search/ [17.03.2019]

${ }^{3}$ Ek bilgi için https://www.gallup.com/analytics/232838/world-poll.aspx adresine bak1labilir.
} 
yaşamlarını 0 ile 10 değerlerinden oluşan bir merdivende hangi basamakta konumlandırdıkları sorulmuştur. Ülkelerin bu endekste sahip oldukları mutluluk seviyeleri ankete katılan bireylerin yaşam değerlendirmelerini altı temel değişkene - kişi başına milli gelir, sosyal destek, sağlıklı yaşam beklentisi, seçimlerini yapmak konusunda özgürlük, cömertlik ve yolsuzluk algısınabağlıdır.

Kurumsal değişken olarak ise aşağıda detaylı olarak tanımlanan altı DBYG ve genel bir gösterge olarak bu değişkenlerin birinci temel bileşeni (Yönetişim) kullanılacaktır"

1. Yolsuzluğun kontrolü (CC), geleneksel olarak kamu gücünün özel kazanç için kullanılması olarak tanımlanan yolsuzluk algısını ölçer.

2. Devletin etkinliği (GE), kamu hizmeti sunumunun kalitesi, bürokrasinin niteliği, memurların yeterliliği, kamu hizmetinin politik baskılardan bağımsızlığı ve hükümetin politikalara taahhüdünün güvenilirliğine ilişkin algıyı ölçer.

3. Politik istikrar ve şiddetin yokluğu (PS), hükümetin anayasaya aykırı ya da terörizm de dâhil olmak üzere şiddet içeren yöntemlerle istikrarsızlaştırılması ihtimaline yönelik algıyı ölçer.

4. Düzenleyici kalite (RQ), fiyat kontrolleri veya yetersiz banka denetimi gibi piyasa dostu olmayan politikaların yanı sıra dış ticaret ve iş geliştirme gibi alanlarda aşırı düzenlemenin getirdiği yüklere ilişkin algıyı ölçer.

5. Hukukun üstünlüğü kuralı (RL), vatandaşların toplum kurallarına ne ölçüde uyduğu ve güven duyduğuna ilişkin çeşitli göstergelerden oluşmaktadır. Bunlar arasında, suç oranı, yargının etkinliği ve öngörülebilirliği ile sözleşmelerin uygulanabilirliğine ilişkin algı yer almaktadır.

6. Iffade ve hesap verebilirlik (VA), siyasi süreç, sivil özgürlükler ve siyasi hakların çeşitli yönlerini ölçen göstergelerden oluşmaktadır. $\mathrm{Bu}$ göstergeler, bir ülkenin vatandaşlarının hükümet seçimine ne ölçüde katılabileceğini ölçmektedir. VA aynı zamanda siyasi otoritenin denetlenmesi ve hesap verebilir olmasında önemli rolü olan medyanın bağımsızlığına ilişkin göstergeleri içerir.

$\mathrm{Bu}$ endeksler gelişmiş ve gelişmekte olan ülkelerden çok sayıda birey ve firmanın görüşlerini yansıtmaktadır ve çeşitli düşünce kuruluşları, sivil toplum örgütleri, uluslararası kuruluşlar ve özel sektör firmaları tarafından üretilen otuzdan fazla bireysel veri kaynağına dayanmaktadır. Endeksler -2.5 ve 2.5

\footnotetext{
4 Birinci temel bileşen yorumlamanın kolay olması için 0-100 arasında dağılacak şekilde ölçeklenmiştir. Yapılan hesaplamalara göre birinci temel bileşen tekil endekslerdeki değişkenliğin yaklaşık \%90'ını açıklamaktadır ve her biriyle pozitif korelasyona sahiptir. Ayrıca, birinci temel bileşen değişkeniyle elde edilen sonuçlarla göstergelerim aritmetik ortalamasının kullanıldığı tahmin sonuçları oldukça benzer çıkmaktadır.
} 
arasında değer almaktadır ve endeksin büyümesi daha iyi yönetişim anlamına gelmektedir. Ancak verilerin daha anlaşılır yorumlanabilmesi amacıyla analizden önce 0 ve 100 arasında dağılacak şekilde yeniden ölçeklenmiştir.

Gerek mutluluğun gerekse de kurumların ölçülmesinde belirli bir sübjektivite dolayısıyla da veride bir gürültü (noise) söz konusudur. Ancak literatürdeki pek çok çalışma bireylerin belirttikleri mutluluk düzeylerinin işsizlik, bağımlılık, boşanma ve depresyon gibi değişkenlerle ilişikli olduğunu göstermektedir. Dolayısıyla, mutluluk değişkeninin bireylerin gerçek faydasını yansıttığını söyleyebiliriz (Di Tella ve MacCulloch, 2006: s. 28). Kurumlara ilişkin olarak ise "gürültü" problemini azaltmak için literatürdeki çoğu makalenin aksine tek bir kurum değişkeni yerine (örneğin demokrasi) birden fazla değişken ve bunların birinci temel bileşeni kullanılmaktadır.

İlgili literatüre göre mutluluğu kurumsal değişkenler yanında başka pek çok faktör de etkilemektedir ${ }^{5}$. Bu nedenle çalışmada zenginliği kontrol etmek için kişi başına reel milli gelir, konjonktürel faktörleri ölçmek için ekonomik büyüme ve enflasyon, güven algısını kontrol etmek için ise sosyal destek değişkeni kullanılacaktır. Sosyal destek değişkeni Dünya Mutluluk Raporu verilerinden alınmıştır ve anketlerde sorulan şu soruya cevabı yansıtmaktadır: "Başınız beladaysa, ihtiyaç duyduğunuzda size yardımcı olmak için güvenebileceğiniz akrabalarınız veya arkadaşlarınız var mı?”. Diğer makro değişkenler ise Dünya Bankası Kalkınma Göstergelerinden alınmıştır (Dünya Bankası, 2018). Sonuç olarak dengesiz panel veri seti 131 ülkeden oluşmaktadır ve 2005-2016 yıllarını kapsamaktadır. Tablo 1 ekonometrik analizde kullanılacak olan değişkenlerin özet istatistiklerini göstermektedir.

Tablo 1. Özet İstatistikler

\begin{tabular}{cccccc}
\hline \hline Değişken & Gözlem & Ortalama & Standart sapma & Min. & Maks. \\
\hline Mutluluk & 1245 & 5.50 & 1.12 & 2.70 & 7.97 \\
Log gelir & 1124 & 9.26 & 1.16 & 6.37 & 11.49 \\
Büyüme (t-1) & 1245 & 2.29 & 3.70 & -22.22 & 17.99 \\
Enflasyon (t-1) & 1245 & 5.08 & 5.61 & -8.98 & 59.22 \\
Sosyal destek & 1236 & 0.82 & 0.11 & 0.29 & 0.99 \\
Yönetişim & 1128 & 53.04 & 22.2 & 10.23 & 100 \\
\hline
\end{tabular}

Tablo 2 ise değişkenler arası korelasyonu göstermektedir. Analizlerde büyüme enflasyon gibi konjonktürel değişkenlerin gecikmeli etkileri nedeniyle bir önceki yıldaki değerleri kullanılmıştır. Beklentilerle tutarlı olarak mutluluk

\footnotetext{
${ }^{5}$ Literatürde mutluluğu bireysel anlamda etkileyen gelir, cinsiyet, yaş, eğitim seviyesi, medeni durum, çocuk sahipliği, sağlık vb. pek çok değişken olduğu tartışılmaktadır. Ancak bu çalışma bireysel değil ülkeler arası mutluluk farklarını açıklamayı amaçladığından bu tip değişkenler modele dâhil edilememektedir.
} 
ve gelir, sosyal destek ve yönetişim arasında pozitif bir korelasyon vardır. Enflasyon mutluluk korelasyonu ise negatif görünmektedir. Tablodaki tek ilginç sonuç ise büyüme ve mutluluk arasındaki negatif ilişkidir. Ancak ikili korelasyondan ibaret olan bu sonucun tüm faktörleri bir arada ele aldığımız ekonometrik modelde değişmesini bekliyoruz.

Tablo 2. Korelasyon Tablosu

\begin{tabular}{ccccccc}
\hline \hline & Mutluluk & $\log$ Gelir & $\begin{array}{c}\text { Büyüme } \\
(\mathrm{t}-1)\end{array}$ & $\begin{array}{c}\text { Enflasyon } \\
(\mathrm{t}-1)\end{array}$ & $\begin{array}{c}\text { Sosyal } \\
\text { destek }\end{array}$ & Yönetişim \\
\hline Mutluluk & 1 & & & & & \\
log Gelir & 0.77 & 1 & & & & \\
Büyüme (t-1) & -0.13 & -0.18 & 1 & & & \\
Enflasyon (t-1) & -0.26 & -0.31 & 0.12 & 1 & & \\
Sosyal destek & 0.71 & 0.66 & 0.10 & -0.18 & 1 & 1 \\
Yönetişim & 0.70 & 0.76 & -0.18 & -0.40 & 0.57 & 1 \\
\hline
\end{tabular}

Yönetişim ve mutluluk arasındaki korelasyonu serpilme diyagramıyla görselleştirebiliriz. $\mathrm{Bu}$ amaçla, analize dahil edilen ülkelerin ortalama mutlulukları ortalama gelir ve yönetişim üzerinde regress edilmiştir. Aşağıda bulunan Grafik 1, gelir kontrol ediliyorken yönetişimin mutluluk üzerindeki etkisini göstermektedir.

Grafik 1. Mutluluk ve Yönetişim

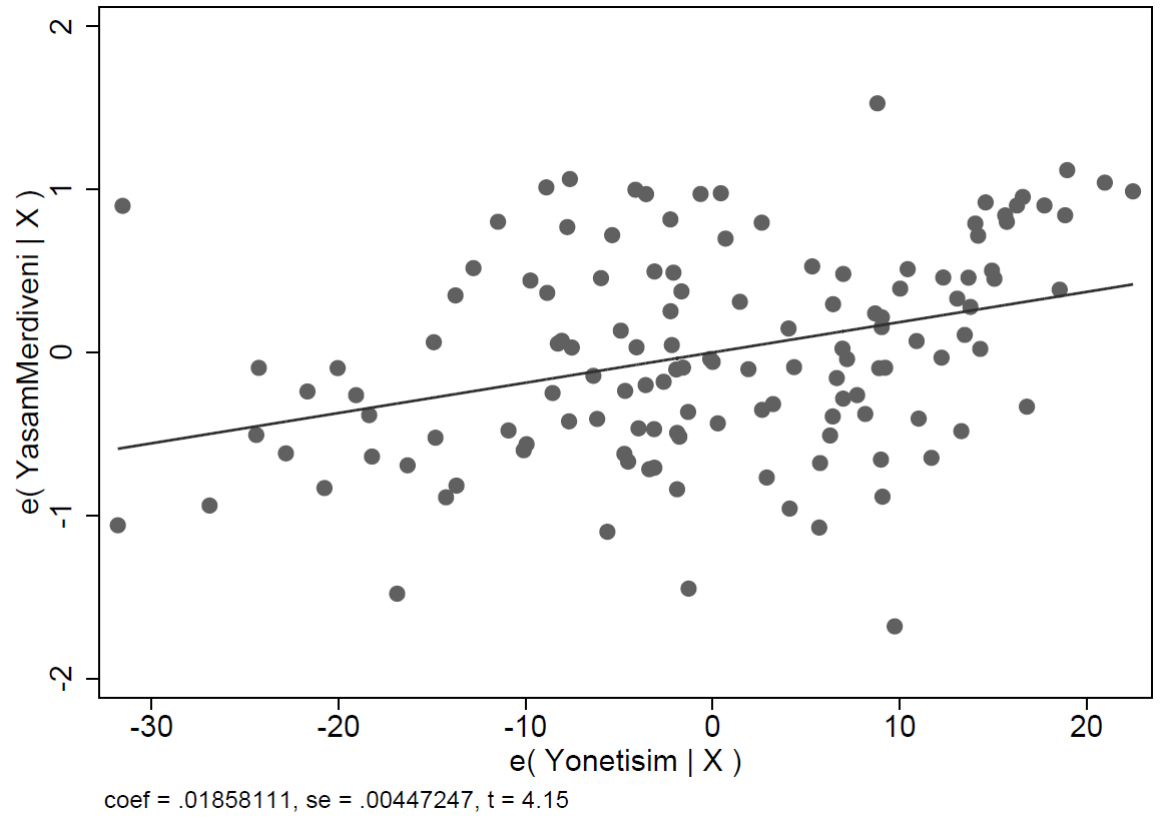

Buna göre ülkelerin gelir seviyelerinden bağımsız olarak yönetişim ile mutluluk arasında pozitif bir ilişki vardır ve bu ilişki 0 p-değeri ile istatistiki olarak anlamlıdır. 


\section{EKONOMETRÍK ANALIZ}

$\mathrm{Bu}$ bölümde, hem zamanla değişmeyen bölge sabit etkilerin hem de bölgeye göre değişmeyen zaman etkilerinin dahil edildiği ülkeler arası bir panel veri modeli tanımlayacağız. Regresyon denklemi aşağıda belirtilmektedir:

$$
M_{i t}=\alpha+\boldsymbol{\beta}_{1} \boldsymbol{Y}_{i t}+\boldsymbol{\theta}^{\prime} \boldsymbol{Z}_{i t}+\eta_{i}+\lambda_{t}+\epsilon_{i t},
$$

Denklemde $\mathrm{M}$ mutluluk endeksini, Y yönetişim değiş̧kenini $\boldsymbol{Z}_{i t}$ vektörü kontrol değişkenlerini, $\eta_{i}, \lambda_{t}$, ve $\epsilon_{i t}$ ise sırasıyla ülke sabit etkileri, zaman sabit etkileri, ve hata terimini göstermektedir.

Tablo 3. Mutluluk ve Yönetişim

\begin{tabular}{|c|c|c|c|c|c|}
\hline & (1) & (2) & (3) & (4) & (5) \\
\hline Yönetişim & $\begin{array}{c}0.031 * * * \\
(0.008)\end{array}$ & $\begin{array}{c}0.020 * * \\
(0.008)\end{array}$ & $\begin{array}{c}0.021 * * \\
(0.008)\end{array}$ & $\begin{array}{c}0.021 * * \\
(0.008)\end{array}$ & $\begin{array}{c}0.018 * * \\
(0.008)\end{array}$ \\
\hline log Gelir & & $\begin{array}{c}0.941 * * * \\
(0.310)\end{array}$ & $\begin{array}{c}0.832 * * * \\
(0.314)\end{array}$ & $\begin{array}{c}0.829 * * * \\
(0.315)\end{array}$ & $\begin{array}{c}0.721 * * \\
(0.304)\end{array}$ \\
\hline Büyüme (t-1) & & & $\begin{array}{c}0.008 \\
(0.005)\end{array}$ & $\begin{array}{c}0.007 \\
(0.005)\end{array}$ & $\begin{array}{c}0.005 \\
(0.005)\end{array}$ \\
\hline Enflasyon (t-1) & & & & $\begin{array}{l}-0.003 \\
(0.004)\end{array}$ & $\begin{array}{l}-0.003 \\
(0.004)\end{array}$ \\
\hline $\begin{array}{l}\text { Sosyal } \\
\text { destek }\end{array}$ & & & & & $\begin{array}{c}1.661 * * * * \\
(0.381)\end{array}$ \\
\hline Ülke S.E. & Evet & Evet & Evet & Evet & Evet \\
\hline Y1l S.E. & Evet & Evet & Evet & Evet & Evet \\
\hline $\mathrm{N}$ & 1128 & 1124 & 1124 & 1124 & 1116 \\
\hline Ülke sayısı & 131 & 131 & 131 & 131 & 131 \\
\hline
\end{tabular}

Not: Tüm regresyonlar sabit terim içermektedir. Robust standart hatalar parantez içerisindedir. ${ }^{*} p$ $<0.1, * * p<0.05, * * * p<0.01$.

Tablo 3 sabit etkiler modeli sonuçlarını göstermektedir. Birinci sütunda modele yalnızca Yönetişim değişkeni dâhil edilmiştir. Buna göre yönetişim ile mutluluk arasında pozitif ve anlamlı bir ilişki vardır. Daha sonra ikinci sütunda logaritmik gelir değişkeni, üçüncü sütunda ekonomik büyüme, dördüncü sütunda enflasyon, beşinci sütunda ise sosyal destek değişkeni modele eklenmiştir. Sonuçlara göre kontrol değişkenleri eklendikçe Yönetişim değişkeninin katsayısında küçük bir azalış olsa da 0.05 düzeyinde anlamlılığını korumaktadır. Katsayıyı yorumlamak gerekirse Yönetişimdeki 1 standart sapmalık artış mutluluğu 0.41 puan artırmaktadır (Sütun 5). Kontrol değişkenlerine baktığımızda ise yalnızca reel kişibaşına düşen milli gelir ile sosyal destek değişkenlerinin pozitif ve anlamlı olduklarını, ekonomik büyüme ve enflasyon gibi konjonktürel değişkenlerin ise - beklenen işaretlere sahip olmalarına rağmen - anlamsız olduklarını görmekteyiz. Buna göre reel milli geliri \%10 daha fazla olan bir ülkenin mutluluk seviyesi 7.24 birim daha yüksek olacaktır. Bu sonuçlar literatürdeki pek çok bulguyla uyumludur (Deaton, 2008; Djankov vd., 2016; Fereidouni vd., 2013; Inglehart, Foa, Peterson ve Welzel, 2008). Easterlin paradoksunun gösterdiği gibi gelir seviyesi daha yüksek olan ülkelere düşük gelirli ülkelere göre daha mutludur. Ancak ekonomik büyüme mutlaka daha 
yüksek mutluluk sağlamaz. Ayrıca, sosyal desteklerdeki 1 standart sapmalık artış da mutluluk seviyesinde 0.187 puanlık bir artış getirmesi beklenmektedir.

Dördüncü bölümde tartışıldığı üzere Yönetişim değişkeni Dünya Bankası'nın yayınladığı göstergelerin aritmetik ortalaması olarak hesaplanmıştır. Dolayısıyla kullanılan altı farklı değişkenin mutluluk üzerinde farklı etkileri olabilir. Bu nedenle Tablo 4'de yönetişim alt endeksleri regresyon modeline teker teker dâhil edilmiş ve sonuçlar gösterilmiştir. Tahmin sonuçlarına göre yolsuzluğun kontrolü ve hükümetin etkinliği mutluluk üzerinde pozitif ve anlamlı bir etkiye sahiptir. Bu değişkenlerdeki 1 standart sapmalık artış mutluluk üzerinde sirasıyla 0.23 ve 0.45 puanlık artışa neden olmaktadır. Diğer değişkenler ise istatistiksel olarak anlamsızdır. Kontrol değişkenlerine baktığımızda ise Tablo 3'de olduğu gibi yalnızca reel gelir ve sosyal destek değişkenleri mutluluk üzerinde pozitif ve anlamlı bir etkiye sahiptir.

Tablo 4. Mutluluk ve Yönetişim Bileşenleri

\begin{tabular}{|c|c|c|c|c|c|c|c|}
\hline & (1) & (2) & (3) & (4) & (5) & (6) & (7) \\
\hline Yönetişim & $\begin{array}{c}0.023 * * \\
(0.010)\end{array}$ & & & & & & \\
\hline $\mathrm{CC}$ & & $\begin{array}{l}0.011^{*} \\
(0.006)\end{array}$ & & & & & \\
\hline GE & & & $\begin{array}{c}0.023 * * * \\
(0.007)\end{array}$ & & & & \\
\hline PS & & & & $\begin{array}{c}0.004 \\
(0.004)\end{array}$ & & & \\
\hline RL & & & & & $\begin{array}{c}0.009 \\
(0.008)\end{array}$ & & \\
\hline RQ & & & & & & $\begin{array}{c}0.005 \\
(0.007)\end{array}$ & \\
\hline VA & & & & & & & $\begin{array}{l}-0.000 \\
(0.006)\end{array}$ \\
\hline log Gelir & $\begin{array}{c}0.724 * * \\
(0.304)\end{array}$ & $\begin{array}{c}0.85^{* * * *} \\
(0.310)\end{array}$ & $\begin{array}{c}0.771 * * \\
(0.319)\end{array}$ & $\begin{array}{c}0.893 * * * \\
(0.309)\end{array}$ & $\begin{array}{c}0.878 * * * \\
(0.301)\end{array}$ & $\begin{array}{c}0.895^{* * *} \\
(0.311)\end{array}$ & $\begin{array}{c}0.966^{* * * *} \\
(0.310)\end{array}$ \\
\hline $\begin{array}{l}\text { Büyüme (t- } \\
\text { 1) }\end{array}$ & 0.005 & 0.005 & 0.005 & 0.004 & 0.004 & 0.004 & 0.004 \\
\hline \multirow{3}{*}{$\begin{array}{l}\text { Enflasyon } \\
(\mathrm{t}-1)\end{array}$} & $(0.005)$ & $(0.005)$ & $(0.005)$ & $(0.005)$ & $(0.005)$ & $(0.005)$ & $(0.005)$ \\
\hline & -0.003 & -0.003 & -0.003 & -0.003 & -0.003 & -0.003 & -0.003 \\
\hline & $(0.004)$ & $(0.004)$ & $(0.004)$ & (0.004) & $(0.004)$ & $(0.004)$ & $(0.004)$ \\
\hline $\begin{array}{l}\text { Sosyal } \\
\text { destek }\end{array}$ & $\begin{array}{c}1.66 * * * \\
(0.382)\end{array}$ & $\begin{array}{l}1.68 * * * \\
(0.373)\end{array}$ & $\begin{array}{c}1.621 * * * \\
(0.371)\end{array}$ & $\begin{array}{c}1.729 * * * \\
(0.384)\end{array}$ & $\begin{array}{c}1.690 * * * \\
(0.376)\end{array}$ & $\begin{array}{c}1.707 * * * \\
(0.371)\end{array}$ & $\begin{array}{c}1.731 * * * \\
(0.380)\end{array}$ \\
\hline Ülke S.E. & Evet & Evet & Evet & Evet & Evet & Evet & Evet \\
\hline Y1l S.E. & Evet & Evet & Evet & Evet & Evet & Evet & Evet \\
\hline $\mathrm{N}$ & 1116 & 1116 & 1116 & 1116 & 1116 & 1116 & 1116 \\
\hline Ülke sayısı & 131 & 131 & 131 & 131 & 131 & 131 & 131 \\
\hline
\end{tabular}

Not: Tüm regresyonlar sabit terim içermektedir. Robust standart hatalar parantez içerisindedir. ${ }^{*} p$ $<0.1, * * p<0.05, * * * p<0.01$. 
Tablo 4'e göre kontrol değişkenleri arasında yalnızca gelirin anlamlı olduğunu görüyoruz. Ayrıca yönetişim alt endekslerinden yalnızca ikisi istatistiksel olarak anlamlıdır. Diğer değişkenlerin anlamsız olmasına yol açabilecek bir etken yönetişimin mutluluk üzerindeki etkisinin gelire bağlı olması olabilir. Buna göre iyi yönetişim mutluluğu gelir seviyesi farkl1 olan ülkelerde farklı şekillerde etkileyebilir. Aynı zamanda anlamlı olan yönetişim değişkenleri gelir seviyesi dikkate alındığında anlamlılığını kaybedebilir. Bu ilişkiyi yakalamanın bir yolu yönetişim endekslerini gelirle etkileşime sokarak regresyona dahil etmektir. Ancak regresyon katsayılarını daha iyi yorumlayabilmek için endeksleri ortalamadan çıkarılmış gelir değişkeniyle etkileşime sokmayı tercih ediyoruz. Böylece yönetişim katsayıları ortalama gelire sahip bir ülkede mutluluğa olan etkiyi ölçmektedir.

Tablo 5 etkileşim değişkenlerinin dahil edildiği model sonuçlarını göstermektedir. Sonuçlar Tablo 3 ile karşılaştırıldığında daha önce anlamlı olan Yönetişim, yolsuzluğun kontrolü ve hükümetin etkinliği değişkenlerine ek olarak hukukun üstünlügü değişkeni de pozitif ve istatistiksek olarak anlamlıdır. Daha da önemlisi katsayıların neredeyse birbirine eşit olduğu görülmektedir. Yani yukarıda yorumladığımız katsayılar örneklemde ortalama gelir seviyesine sahip ülkeler üzerindeki etkileri göstermektedir. Dolayısıyla Tablo 3'de bulduğumuz sonuçların gelir etkileşimlerinin dâhil edilmesine karşı robust olduğu görülmektedir. Tahmin sonuçlarını farklı bir şekilde yorumlayacak olursak, ortalama gelir seviyesine sahip 2 ülkeden biri Yönetişim, yolsuzluğun kontrolü, hükümetin etkinliği ve hukukun üstünlüğü endekslerinden 25. yüzdelik dilime diğeri ise 75 . yüzdelik dilime giriyor olsun. Bu iki grup ülke arasındaki mutluluk farkı yaklaşık olarak sırasıyla $0.74,0.31,0.71$ ve 0.40 olacaktır.

Tablo 5. Mutluluk ve Yönetişim: Gelirin Rolü

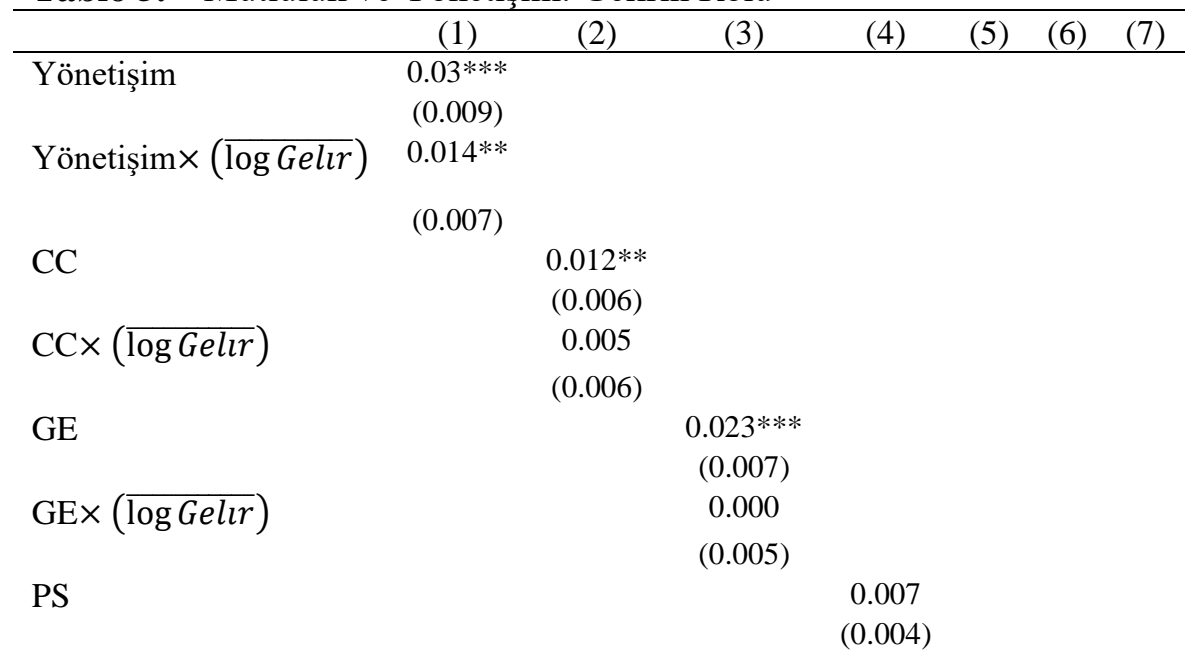




\section{Tablo 5'in devamı...}

PS $\times$

$(\overline{\log \text { Gelır }})$

RL

RLX

$(\overline{\log G e l l r})$

RQ

RQ×

( $\overline{\log \text { Gelır }}$ )

VA

$\mathrm{VAx}$

$(\overline{\log G e l \imath r})$
0.004

$(0.002)$

$$
\begin{gathered}
0.013^{*} \\
(0.007) \\
0.009
\end{gathered}
$$

(0.006)

0.006

$(0.007)$

$0.011 *$

$(0.006)$

0.005

(0.006)

$0.010^{*}$

$(0.005)$

$\log$ Gelir

$\begin{array}{cc}0.035 & 0.618 \\ (0.446) & (0.423)\end{array}$

$0.753^{*}$

$0.720 * *$

0.453

(0.385)

0.373

(0.401)

0.502

(0.325)

0.004

0.003

$(0.364)$

Büyüme (t-

0.005

0.003

(0.005)

(0.005)

$-0.004$

$-0.004$

$(0.005)$

Enflasyon

$$
\begin{array}{ll}
(0.005) \quad(0.005) \\
-0.005 & -0.003
\end{array}
$$

$-0.003$

$-0.003$

(0.004)

(0.004) (0.004)

(0.004)

(0.004)

(0.004)

$1.857 * * *$

(0.004)

Sosyal

$$
1.78 * * * \quad 1.726 * * * \quad 1.625 * * *
$$

$1.757 * * *$

$1.761 * * *$

(0.353)

(0.368)

Ülk.

(0.357)

(0.356)

(0.370)

(0.374)

(0.359)

Evet

Evet

Evet

1116

131

$1116 \quad 1116$

131

131

1116
131

1116

Evet

Ülke sayısı

131

131

131 1116

Not: Tüm regresyonlar sabit terim içermektedir. Robust standart hatalar parantez içerisindedir. ${ }^{*} p$ $<0.1, * * p<0.05, * * * p<0.01$.

\section{A. Sağlamlık (Robustness) Analizleri}

Sabit etkiler modeli her ne kadar zamana bağlı olarak değişmeyen kültür ve din gibi faktörleri kontrol etse de ters nedensellik nedeniyle endojenlik sorunu ortaya çıkabilir. Örneğin kurumsal gelişme mutluluğu artırmıyor da mutluluğun daha yüksek olduğu ülkelerde daha gelişmiş kurumlar ortaya çıkıyor olabilir. Ters nedensellik sorununu çözmek için kullanılabilecek olan bir yöntem Arellano ve Bond (1991) tarafindan geliştirilen fark Genelleştirilmiş Momentler Metodur (GMM). Bu yöntem ilk önce sabit etkileri ortadan kaldırmak için birinci fark alır, sonrasında ise bağımlı değişkenin gecikmelerini araç değişken olarak kullanır. Fark GMM regresyon sonuçları Tablo 6' da gösterilmektedir. 
Tahmin sonuçlarına göre mutluluğun gecikmeli değeri beklendiği üzere pozitif ve anlamlıdır. Ancak gecikme katsayısı yaklaşık olarak 0.28 civarındadır, yani mutlulukta çok güçlü olmayan bir süreklilik vardır. 1. sütunda Yönetişim değişkeninin katsayısı sabit etkiler modeline kıyasla daha küçük olsa da pozitif ve anlamlı olduğu görülmektedir. Tekil kurumsal değişkenlerden hükümetin etkinliği ve politik istikrarın mutlulukla pozitif ilişkili olduğu sonucu çıkmaktadır. Tablo 6'nın alt satırlarında yer alan AR(2) katsayısı istatistiksel olarak anlamsızdır. Yani 2. Dereceden otokorelasyon yoktur boş hipotezi reddedilemez. Ayrıca araç değişkenlerin geçerliliği için yapılan Sargan testine göre bu değişkenlerin geçerli olduğu boş hipotez reddedilemez. Sonuç olarak fark GMM tahmin sonuçları spesifikasyon testlerini geçmektedir.

Tablo 6. Mutluluk ve Yönetişim Bileșenleri, Fark GMM

\begin{tabular}{|c|c|c|c|c|c|c|c|}
\hline & (1) & (2) & (3) & (4) & (5) & (6) & (7) \\
\hline Mutluluk & $\begin{array}{c}0.279 * * * \\
(0.101)\end{array}$ & $\begin{array}{c}0.273^{* * * *} \\
(0.103)\end{array}$ & $\begin{array}{c}0.272^{* * * *} \\
(0.103)\end{array}$ & $\begin{array}{c}0.291 * * * \\
(0.101)\end{array}$ & $\begin{array}{c}0.288 * * * * \\
(0.102)\end{array}$ & $\begin{array}{c}0.282 * * * * \\
(0.103)\end{array}$ & $\begin{array}{c}0.279 * * * \\
(0.099)\end{array}$ \\
\hline Yönetişim & $\begin{array}{r}0.018 * * \\
(0.008)\end{array}$ & & & & & & \\
\hline $\mathrm{CC}$ & & $\begin{array}{c}0.011 \\
(0.008)\end{array}$ & & & & & \\
\hline GE & & & $\begin{array}{c}0.017 * * \\
(0.007)\end{array}$ & & & & \\
\hline PS & & & & $\begin{array}{l}0.007 * \\
(0.003)\end{array}$ & & & \\
\hline RL & & & & & $\begin{array}{c}0.003 \\
(0.008)\end{array}$ & & \\
\hline RQ & & & & & & $\begin{array}{l}-0.013 \\
(0.008)\end{array}$ & \\
\hline VA & & & & & & & $\begin{array}{c}0.012 \\
(0.008)\end{array}$ \\
\hline Log Gelir & $\begin{array}{c}0.467 \\
(0.444)\end{array}$ & $\begin{array}{c}0.576 \\
(0.433)\end{array}$ & $\begin{array}{c}0.568 \\
(0.423)\end{array}$ & $\begin{array}{c}0.546 \\
(0.448)\end{array}$ & $\begin{array}{c}0.622 \\
(0.445)\end{array}$ & $\begin{array}{l}0.798^{*} \\
(0.453)\end{array}$ & $\begin{array}{c}0.581 \\
(0.437)\end{array}$ \\
\hline $\begin{array}{l}\text { Büyüme } \\
(\mathrm{t}-1)\end{array}$ & 0.004 & 0.003 & 0.003 & 0.003 & 0.003 & 0.002 & 0.004 \\
\hline & $(0.005)$ & $(0.005)$ & $(0.005)$ & $(0.005)$ & $(0.005)$ & $(0.005)$ & $(0.005)$ \\
\hline $\begin{array}{l}\text { Enflasyon } \\
(\mathrm{t}-1)\end{array}$ & $\begin{array}{l}-0.000 \\
(0.004)\end{array}$ & $\begin{array}{l}-0.000 \\
(0.004)\end{array}$ & $\begin{array}{l}0.000 \\
(0.004)\end{array}$ & $\begin{array}{l}-0.001 \\
(0.004)\end{array}$ & $\begin{array}{l}-0.000 \\
(0.004)\end{array}$ & $\begin{array}{l}-0.000 \\
(0.004)\end{array}$ & $\begin{array}{l}-0.000 \\
(0.004)\end{array}$ \\
\hline $\begin{array}{l}\text { Sosyal } \\
\text { destek } \\
\text { Y1l S.E. }\end{array}$ & $\begin{array}{c}1.204 * * * \\
(0.382) \\
\text { EVET }\end{array}$ & $\begin{array}{c}1.218 * * * \\
(0.378) \\
\text { EVET }\end{array}$ & $\begin{array}{c}1.182 * * * \\
(0.385) \\
\text { EVET }\end{array}$ & $\begin{array}{c}1.220 * * * \\
(0.382) \\
\text { EVET }\end{array}$ & $\begin{array}{c}1.201 * * * \\
(0.387) \\
\text { EVET }\end{array}$ & $\begin{array}{c}1.204 * * * \\
(0.380) \\
\text { EVET }\end{array}$ & $\begin{array}{c}1.227 * * * \\
(0.379) \\
\text { EVET }\end{array}$ \\
\hline $\mathrm{N}$ & 783 & 783 & 783 & 783 & 783 & 783 & 783 \\
\hline $\begin{array}{l}\text { Ülke } \\
\text { Say1s1 }\end{array}$ & 127 & 127 & 127 & 127 & 127 & 127 & 127 \\
\hline Enstrüman & 50 & 50 & 50 & 50 & 50 & 50 & 50 \\
\hline AR1 & 0.00 & 0.00 & 0.00 & 0.00 & 0.00 & 0.00 & 0.00 \\
\hline AR2 & 0.13 & 0.15 & 0.11 & 0.17 & 0.15 & 0.17 & 0.15 \\
\hline Sargan & 0.08 & 0.06 & 0.08 & 0.08 & 0.08 & 0.08 & 0.08 \\
\hline
\end{tabular}

Not: Tüm regresyonlar sabit terim içermektedir. Robust standart hatalar parantez içerisindedir. ${ }^{*} p$ $<0.1, * * p<0.05, * * * p<0.01$. 
Bir diğer sağlamlık analizi ülke guruplarını dikkate alınarak yapılabilir. Her ne kadar sabit etkiler modeli tahmin ediyor ve gelir, büyüme gibi değişkenleri kontrol ediyor olsak da örneklememizde çok farklı yapılarda ülkeler bulunmaktadır. Ülke heterojenliğinin tahmin sonuçlarını etkileyip etkilemediğinin belirlenmesi için Tablo 7'de farklı ülke gurupları örneklemden çıkarılarak analiz tekrar edilmiştir. Sırasıyla AB, yükselen piyasalar, OECD ülkeleri ve gelişmiş ülkelerin örneklemden dişlandığı durumlarda Yönetişim değişkeninin pozitif ve anlamlı olduğu görülmektedir. Dolayısıyla temel sonuçların ülke heterojenliğine karşı sağlamdır.

Tablo 7. Mutluluk ve Yönetişim: Ülke Alt Guruplarının Dişlanması

\begin{tabular}{lcccc}
\hline \multirow{2}{*}{ Hariç: } & $(1)$ & $(2)$ & $(3)$ & $(4)$ \\
& AB & Yükselen & OECD & Gelişmiş \\
& Ülkeleri & Piyasalar & Ülkeleri & Ülkeler \\
\hline Yönetişim & $0.019^{* *}$ & $0.017^{*}$ & $0.019^{* *}$ & $0.017^{*}$ \\
& $(0.008)$ & $(0.009)$ & $(0.009)$ & $(0.009)$ \\
log Gelir & 0.518 & $0.603^{*}$ & 0.457 & 0.329 \\
& $(0.337)$ & $(0.326)$ & $(0.368)$ & $(0.365)$ \\
Büyüme (t-1) & 0.003 & 0.001 & 0.004 & 0.005 \\
& $(0.006)$ & $(0.006)$ & $(0.006)$ & $(0.006)$ \\
Enflasyon (t-1) & -0.002 & -0.004 & -0.003 & -0.003 \\
& $(0.004)$ & $(0.004)$ & $(0.004)$ & $(0.004)$ \\
Sosyal & $1.534 * * *$ & $1.694 * * *$ & $1.643 * * *$ & $1.545 * * *$ \\
destek & $(0.386)$ & $(0.423)$ & $(0.406)$ & $(0.389)$ \\
Ülke S.E. & EVET & EVET & EVET & EVET \\
Y1l S.E. & EVET & EVET & EVET & EVET \\
\hline N & 921 & 882 & 847 & 823 \\
Ülke Sayıs1 & 109 & 105 & 101 & 97 \\
\hline
\end{tabular}

Not: Tüm regresyonlar sabit terim içermektedir. Robust standart hatalar parantez içerisindedir. ${ }^{*} p$ $<0.1, * * p<0.05, * * * p<0.01$.

\section{SONUÇ}

Kurumsal gelişmişlik ile mutluluk arasında bir ilişki var mıdır sorusu mutluluk ekonomisi literatürünün en önemli konularından biri olmuştur. Buna rağmen ampirik makalelerde birbiriyle çelişen sonuçlar dikkat çekmektedir. $\mathrm{Bu}$ çalışmada konuya daha detaylı bakmak adına farklı tanımlara sahip kurumsal değişkenler kullanılmıştır. Daha açık bir ifadeyle, DBYG'ye ait altı farklı yönetişim değişkeninin mutluluk üzerindeki etkisi 2005-2016 y1llarını kapsayan ve 131 ülkeden oluşan örneklemle analiz edilmiştir.

Tahmin sonuçlarına göre yönetişim ile mutluluk arasında pozitif ve anlamlı bir ilişki vardır. Yani yönetişimin daha kaliteli olduğu ülkeler diğerlerine göre daha mutludur. Elde edilen katsayılara göre Yönetişim değişkenindeki 1 standart sapmalık artış mutluluk seviyesinde 0.41 puanlık yükselişe neden olmaktadır. Ayrıca tahmin sonuçları GMM'e ve belirli ülke gruplarının 
dışlanmasına karşı sağlamdır. Dolayısıyla, sonuçlar kurumların ülkelerin mutluluk düzeyleri üzerinde pozitif bir etkiye sahip olduğunu açıkça ortaya koymaktadir.

Detaylarına bakıldığında ise, yolsuzluğun kontrolü ve hükümetin etkinliği değişkenlerinin istatistiksel olarak anlamlı olduğu görülmektedir. Ayrıca gelir seviyeleri dikkate alındığında, ortalama gelire sahip ülkelerden yolsuzluğun kontrolü, hükümetin etkinliği ve hukukun üstünlüğü açısından daha iyi performans gösteren ülkelerde mutluluğun daha yüksek olacağ1 anlaşılmaktadır.

$\mathrm{Bu}$ sonuçlar, ülkelerin hangi gelir düzeyine ya da makroekonomik konjonktüre sahip olursa olsun yönetişim kanallarını iyileştirerek halkın refah seviyesini artırabileceğini göstermektedir. Dolayısıyla mutluluk salt parasal bir olgu değildir. İnsanlar gelirden bağımsız olarak yolsuzluğun kontrol altında olduğu, kamu kaynaklarının etkin ve adil kullanıldığı, hükümetin açıkladığı politikalara bağlı olduğu ve hukukun üstünlüğünden şüphe etmediklerinde mutlulukları artmaktadır. Bu bağlamda, sonuçlar kurumsal kalkınmanın önemini açık bir şekilde gözler önüne sermektedir.

\section{KAYNAKÇA}

Acemoglu, D., Johnson, S., ve Robinson, J. A. (2001). The colonial origins ofcomparative development: An empirical investigation. American economic review, 91(5), 1369-1401. https://www.aeaweb.org/articles?id=10.1257/aer.91.5.1369

Acemoglu, D., Naidu, S., Restrepo, P., ve Robinson, J. A. (2019). Democracy does cause growth. Journal of Political Economy, 127(1), 47-100. https://doi.org/10.1086/700936

Bjørnskov, C., Dreher, A., ve Fischer, J. A. (2008). Cross-country determinants of life satisfaction: Exploring different determinants across groups in society. Social Choice and Welfare, 30(1), 119-173. https://doi.org/10.1007/s00355-007 0225-4

Bjørnskov, C., Dreher, A., ve Fischer, J. A. (2010). Formal institutions and subjective well-being: Revisiting the cross-country evidence. European Journal of Political Economy, 26(4), 419-430. https://doi.org/10.1016/j.ejpoleco.2010.03.001

Bjørnskov, C., ve Tsai, M.C. (2015). How do institutions affect happiness and misery? A tale of two tails. Comparative Sociology, 14(3), 353-385. https://doi.org/10.1163/15691330-12341346 
Djankov, S., Nikolova, E., ve Zilinsky, J. (2016). The happiness gap in Eastern Europe. Journal of Comparative Economics, 44(1), 108-124. https://doi.org/10.1016/j.jce.2015.10.006

Di Tella, R., ve MacCulloch, R. (2006). Some uses of happiness data in economics. Journal of economic perspectives, 20(1), 25-46. https://www.aeaweb.org/articles?id=10.1257/089533006776526111

Dorn, D., Fischer, J. A., Kirchgässner, G., ve Sousa-Poza, A. (2007). Is it culture or democracy? The impact of democracy and culture on happiness. Social Indicators Research, 82(3), 505-526. https://doi.org/10.1007/s11205-006 9048-4

Dorn, D., Fischer, J. A., Kirchgässner, G., ve Sousa-Poza, A. (2008). Direct democracy and life satisfaction revisited: new evidence for Switzerland. Journal of Happiness $\quad$ Studies, $\quad 9(2), \quad$ 227-255. https://doi.org/10.1007/s10902-007-9050-9

Dünya Bankası. (2018, Ocak 11). Worldwide governance indicators. http://info.worldbank.org/governance/wgi/index.asp.

Dünya Bankasi. (2018, Ocak 11). World development indicators. https://databank.worldbank.org/source/world-development-indicators.

Easterlin, R.A. (1974). Does economic growth improve the human lot? Paul A. David ve Melvin W. Reder (Eds.), Nations and Households in Economic Growth: Essays in Honor of Mozes Abramowitz içinde (s. 89125). Academic press, New York.

Frey, B. S., ve Stutzer, A. (2000a). Happiness, economy and institutions. TheEconomic Journal, 110(466), 918938.https://doi.org/10.1111/14680297.00570

Frey, B. S., ve Stutzer, A. (2000b). Happiness prospers in democracy. Journal of happiness Studies, 1(1), 79-102. https://doi.org/10.1023/A:1010028211269

Gallup World Poll. (2019, Mart 17). https://www.gallup.com/

Fereidouni H. G., Najdi, Y., ve Amiri, R. E. (2013). Do governance factors matter for happiness in the MENA region?. International Journal of Social Economics, 40(12), 1028-1040. https://doi.org/10.1108/IJSE-11$\underline{2012-0208}$

Inglehart, R., Foa, R., Peterson, C., ve Welzel, C. (2008). Development, freedom, and rising happiness: A global perspective (1981-2007). Perspectives on psychological science, 3(4), 264-285. https://doi.org/10.1111/j.1745 6924.2008.00078.x 
Inglehart, R. (2006). Democracy and Happiness: What Causes What? Erişim adresi:

https://pdfs.semanticscholar.org/1d0f/1c409f46040281bde732256586faf $\underline{68 \mathrm{e} 0 \mathrm{~d} 2 . p d f}$

Inglehart, R., ve Ponarin, E. D. (2013). Happiness and democracy 1972-2008. Journal of Siberian Federal University, 6(8), 1097-1106.

Kaufmann, D., Kraay, A., ve Mastruzzi, M. (2010). The Worldwide GovernanceIndicators: methodology and analytical issues. World Bank, Policy Research Working Paper 5430.

Nikolova, M. (2016). Minding the happiness gap: Political institutions and perceived quality of life in transition. European Journal of Political Economy, 45, $129 \quad 148$.

https://doi.org/10.1016/j.ejpoleco.2016.07.008

North, D.C. (1990). Institutions, Institutional Change and Economic Performance. Cambridge University Press, Cambridge.

Ott, J. (2005). Level and inequality of happiness in nations: Does greater happiness of a greater number imply greater inequality in happiness?. Journal of Happiness $\quad$ Studies, 6(4), 397-420. https://doi.org/10.1007/s10902-005-8856-6

Ott, J. C. (2010). Good governance and happiness in nations: Technical quality precedes democracy and quality beats size. Journal of HappinessStudies, 11(3), 353-368. https://doi.org/10.1007/s10902-0099144-7

Ott, J. C. (2011). Government and happiness in 130 nations: Good governance fosters higher level and more equality of happiness. Social indicatorsresearch, 102(1), 3-22. https://doi.org/10.1007/s11205-0109719-z

Rodrik, D., Subramanian, A., ve Trebbi, F. (2004). Institutions rule: the primacy of institutions over geography and integration in economic development. Journal of economic growth, 9(2), 131-165. https://doi.org/10.1023/B:JOEG.0000031425.72248.85

Williamson, O. E. (2000). The new institutional economics: taking stock, lookingahead. Journal of economic literature, 38(3), 595-613. https://www.aeaweb.org/articles?id=10.1257/jel.38.3.595

World Happiness Report. (2019, Mart 2). https://worldhappiness.report/

Yay, T., Yay, G. G., ve Aksoy, T. (2018). Impact of institutions on entrepreneurship: a panel data analysis. Eurasian Economic Review, 8(1), 131-160. https://doi.org/10.1007/s40822-017-0082-0 